OPEN ACCESS

Edited by:

Gilberto Igrejas,

Universidade de Trás-os-Montes e

Alto Douro, Portugal

Reviewed by:

Giuseppe Celenza,

Università degli Studi dell'Aquila, Italy

Matej Butala,

University of Ljubljana, Slovenia

${ }^{*}$ Correspondence:

Rahul M. Kohli

rkohli@pennmedicine.upenn.edu

Simon D. P. Baugh

sbaugh@fc-cdci.com

Specialty section:

This article was submitted to

Antimicrobials, Resistance

and Chemotherapy,

a section of the journal

Frontiers in Microbiology

Received: 30 June 2018 Accepted: 16 November 2018 Published: 18 December 2018

Citation:

Selwood T, Larsen BJ, Mo CY, Culyba MJ, Hostetler ZM, Kohli RM, Reitz AB and Baugh SDP (2018)

Advancement of the

5-Amino-1-(Carbamoylmethyl)-1H-

1,2,3-Triazole-4-Carboxamide

Scaffold to Disarm the Bacterial SOS

Response. Front. Microbiol. 9:2961.

doi: 10.3389/fmicb.2018.02961

\section{Advancement of the} 5-Amino-1-(Carbamoylmethyl)-1H1,2,3-Triazole-4-Carboxamide Scaffold to Disarm the Bacterial SOS Response

\author{
Trevor Selwood ${ }^{1,2}$, Brian J. Larsen ${ }^{3}$, Charlie Y. Mo ${ }^{1,2}$, Matthew J. Culyba ${ }^{1,2}$, \\ Zachary M. Hostetler ${ }^{1,2}$, Rahul M. Kohli ${ }^{1,2 *}$, Allen B. Reitz ${ }^{3}$ and Simon D. P. Baugh ${ }^{3 *}$ \\ ${ }^{1}$ Department of Medicine, University of Pennsylvania, Philadelphia, PA, United States, ${ }^{2}$ Department of Biochemistry \\ and Biophysics, University of Pennsylvania, Philadelphia, PA, United States, ${ }^{3}$ Fox Chase Chemical Diversity Center, Inc., \\ Doylestown, PA, United States
}

Many antibiotics, either directly or indirectly, cause DNA damage thereby activating the bacterial DNA damage (SOS) response. SOS activation results in expression of genes involved in DNA repair and mutagenesis, and the regulation of the SOS response relies on two key proteins, LexA and RecA. Genetic studies have indicated that inactivating the regulatory proteins of this response sensitizes bacteria to antibiotics and slows the appearance of resistance. However, advancement of small molecule inhibitors of the SOS response has lagged, despite their clear promise in addressing the threat of antibiotic resistance. Previously, we had addressed this deficit by performing a high throughput screen of $\sim 1.8$ million compounds that monitored for inhibition of RecAmediated auto-proteolysis of Escherichia coli LexA, the reaction that initiates the SOS response. In this report, the refinement of the 5-amino-1-(carbamoylmethyl)-1H-1,2,3triazole-4-carboxamide scaffold identified in the screen is detailed. After development of a modular synthesis, a survey of key activity determinants led to the identification of an analog with improved potency and increased breadth, targeting auto-proteolysis of LexA from both E. coli and Pseudomonas aeruginosa. Comparison of the structure of this compound to those of others in the series suggests structural features that may be required for activity and cross-species breadth. In addition, the feasibility of small molecule modulation of the SOS response was demonstrated in vivo by the suppression of the appearance of resistance. These structure activity relationships thus represent an important step toward producing Drugs that Inhibit SOS Activation to Repress Mechanisms Enabling Resistance (DISARMERs).

Keywords: SOS response, antibiotic resistance, structure activity analysis, Pseudomonas aeruginosa, DNA damage

\section{INTRODUCTION}

Antibiotic resistant bacteria represent one of the most pressing issues in infectious disease research today (Brown and Wright, 2016). An era is fast approaching when many currently treatable infections may become incurable (Boucher et al., 2009). While important efforts are underway to discover antimicrobials with different mechanisms of action (Clatworthy et al., 2007; 
Thaker et al., 2013; Ling et al., 2015), the most conventional approach to overcoming resistance has involved the chemical modification of existing antibiotic scaffolds (Fischbach and Walsh, 2009). Although the resulting "next generation" antibiotics offer a respite, bacteria are likely to rapidly adapt their preexisting resistance mechanisms to counteract these gains. The limitations of conventional approaches highlight the need to pursue alternative strategies.

A promising alternative approach is to target pathways that promote acquired resistance to antibiotics. One such pathway is the bacterial DNA damage response pathway, known as the SOS response (Figure 1). Many antibiotics induce the SOS response, either by inducing DNA damage (e.g., fluoroquinolones) or by indirectly promoting DNA damage via targeting essential cellular and metabolic functions (Kohanski et al., 2007; Dwyer et al., 2012; Mo et al., 2016). The SOS response is well conserved across pathogens and involves numerous genes (e.g., > 40 in Escherichia coli). These proteins include translesion DNA polymerases that promote mutagenesis, recombinases that mobilize antibiotic resistance genes, and proteins that mediate persistence, biofilm formation or directly promote antibiotic evasion (McKenzie et al., 2000; Beaber et al., 2004; Schlacher et al., 2006; Galhardo et al., 2007; Da Re et al., 2009; Dörr et al., 2009, 2010; Gotoh et al., 2010). Thus, suppression of the SOS pathway would be predicted to compromise the response of bacteria to antibiotics.

A means to suppress the SOS pathway is to maintain repression of the SOS response. In the absence of genotoxic stress all genes of the pathway are tightly repressed by the dualfunction repressor/protease, LexA (Figure 1). In the presence of genotoxic stress the DNA damage sensor protein RecA forms filaments along ssDNA generated by aborted replication. The pathway is triggered when this filamentous $\operatorname{RecA}\left(\operatorname{RecA}^{*}\right)$ promotes a conformational change in LexA that brings one of its protein loops into its own serine protease active site (Luo et al., 2001). Subsequent auto-proteolysis destabilizes LexA, and leads to transcriptional de-repression of SOS pathway genes (Culyba et al., 2018).

Genetic studies targeting either RecA or LexA validate the SOS response as a therapeutic target (Figure 1). In a murine thigh infection model an E. coli strain harboring a non-cleavable mutant of LexA abrogated resistance both to ciprofloxacin and rifampicin compared to a strain with a cleavable LexA (Cirz et al., 2005). In addition, deletion of RecA, or forced over expression of non-cleavable LexA have been shown to hypersensitize bacteria to traditional antibiotics (Lu and Collins, 2009; Thi et al., 2011; Mo et al., 2016). Furthermore, SOS inactivation in resistant bacteria resulted in re-sensitization to a fluoroquinolone (Recacha et al., 2017). Together, these studies suggest that targeting the SOS response could lead to both synergy with DNA damaging antibiotics to lower MIC values and suppression of acquired resistance (Cirz and Romesberg, 2007; Smith and Romesberg, 2007; Culyba et al., 2015).

While specifically targeting RecA has produced some important gains (Wigle et al., 2009; Alam et al., 2016; Bellio et al., 2017), we aimed to inhibit the RecA*-induced cleavage of LexA as this represents the key initiating step in the SOS response. To this end we developed a high throughput screen
(HTS) that allowed estimation of RecA $^{*}$-mediated LexA cleavage. Using this screen some 1.8 million compounds were evaluated for inhibition of RecA*-mediated LexA cleavage (Mo et al., 2018). The result of this screen was the identification of several chemotypes with the potential to modulate the SOS response (Mo et al., 2018). Herein is described the advancement of one of the chemotypes, the 5-amino-1(carbamoylmethyl)-1H-1,2,3-triazole-4-carboxamide scaffold (Figure 2) via a modular synthesis that allowed for evaluation of structure-activity relationships and lead improvement to increase potency and expand the breadth of targetable pathogens. This work underscores the feasibility of developing DISARMERs (Drugs to Inhibit SOS Activation to Repress Mechanisms Enabling Resistance) - molecules that can act as adjuvants in standard antimicrobial therapies to both sensitize bacteria to antibiotics and reduce the rise of acquired resistance.

\section{MATERIALS AND METHODS}

\section{Materials}

All reagents used in chemical synthesis were purchased from Aldrich Chemical Co., (Milwaukee, WI, United States), Alfa Aesar (Ward Hill, MA, United States), or Thermo Fisher Scientific (Pittsburgh, PA, United States) and were used without further purification. Chemicals used in biochemical assays were obtained from Sigma-Aldrich (St Louis, MO, United States).

\section{Compound Synthesis}

Compounds were synthesized using a method that proceeds via a [3+2] cycloaddition, allowing facile, catalytic, non-moisture sensitive, and non-air sensitive syntheses of a variety of 5-amino1-(carbamoylmethyl)-1H-1,2,3-triazole-4-carboxamides. For the majority of analogs, catalysts employed were either sodium ethoxide (synthesis A, Table 1) or cesium carbonate (synthesis B, Table 1). The base-mediated cyclization is depicted in Figure 2.

For reactions catalyzed by sodium ethoxide (synthesis A), a solution of sodium ethoxide $(1.2 \mathrm{mmol})$ in anhydrous ethanol $(10 \mathrm{~mL})$ was maintained under nitrogen and cooled to $0^{\circ} \mathrm{C}$ with stirring. Once cooled, the cyano component $(1.1 \mathrm{mmol})$ was added to the solution. The resulting solution was stirred for $10 \mathrm{~min}$ at $0^{\circ} \mathrm{C}$ before addition of the azido component $(1.0 \mathrm{mmol})$. The resulting solution was maintained at $0^{\circ} \mathrm{C}$ for a further $2 \mathrm{~min}$ before being allowed to warm to room temperature. Upon reaching room temperature, the solution was lightly sonicated for $20 \mathrm{~s}$ before the temperature was raised to $40^{\circ} \mathrm{C}$. The solution was maintained at $40^{\circ} \mathrm{C}$ for $4 \mathrm{~h}$ before being allowed to cool to room temperature. Once the solution reached room temperature the reaction was quenched with deionized $\mathrm{H}_{2} \mathrm{O}(100 \mathrm{~mL})$ and extracted with ethyl acetate $(3 \times 50 \mathrm{~mL})$. The combined organic fractions were washed with deionized $\mathrm{H}_{2} \mathrm{O}(50 \mathrm{~mL})$, dried over anhydrous $\mathrm{Na}_{2} \mathrm{SO}_{4}$, filtered, and concentrated in vacuo to yield the crude product. The crude product was dissolved in DMF, filtered through a syringe filter and purified via reverse phase HPLC using acetonitrile in deionized $\mathrm{H}_{2} \mathrm{O}$ (with $0.1 \%$ TFA in both solvents) 


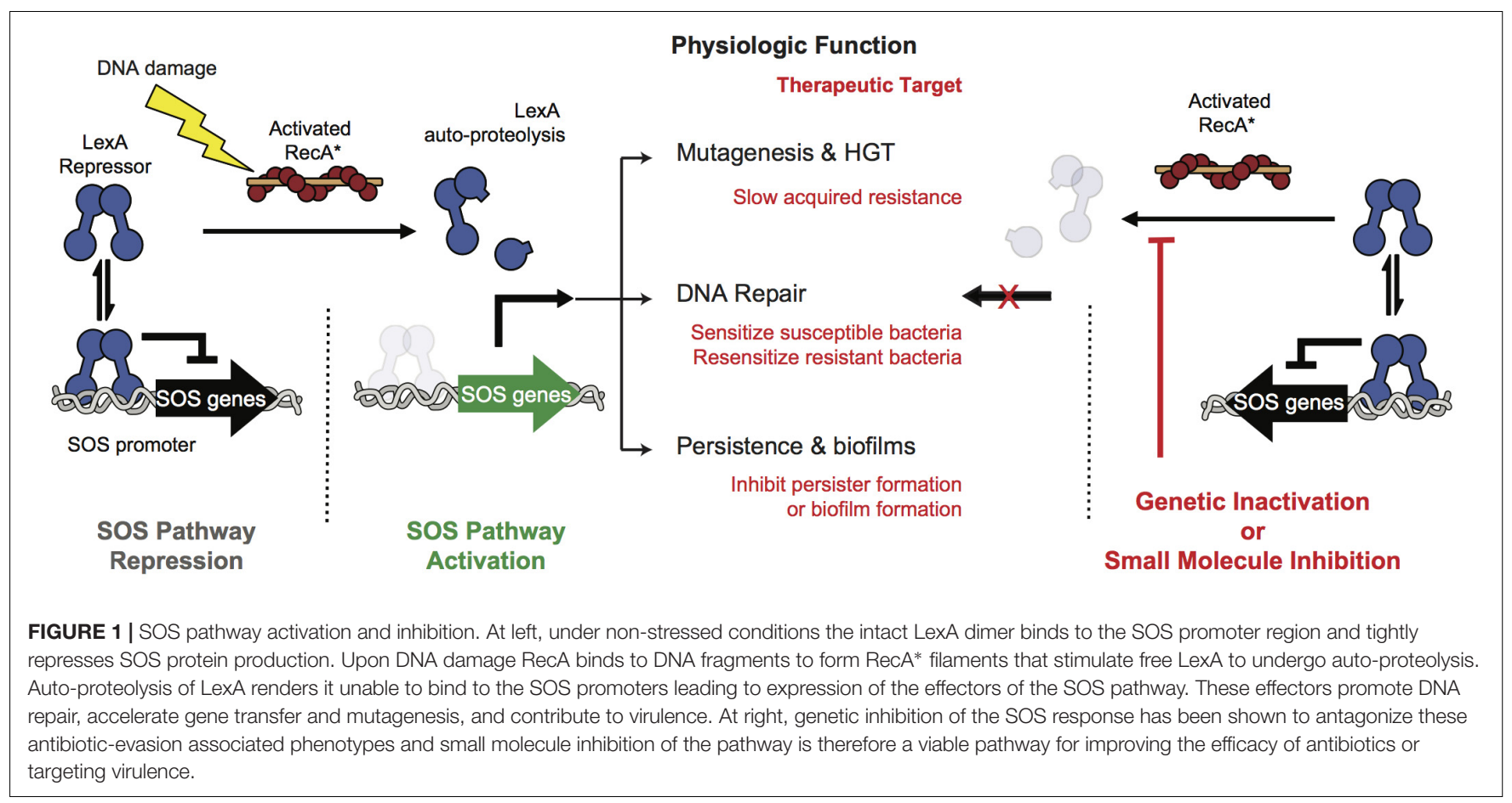

to yield, after evaporation and lyophilization, the desired product.

For reactions catalyzed by cesium carbonate (synthesis B), the azido component $(1.1 \mathrm{mmol})$, the cyano component $(1.0 \mathrm{mmol})$ and cesium carbonate $(0.25 \mathrm{mmol})$ were dissolved in DMSO/deionized $\mathrm{H}_{2} \mathrm{O}(7: 3,4 \mathrm{~mL})$ with stirring. The reaction vial was capped and stirred for $24 \mathrm{~h}$ before being diluted with deionized $\mathrm{H}_{2} \mathrm{O}$, partially concentrated in vacuo, frozen,

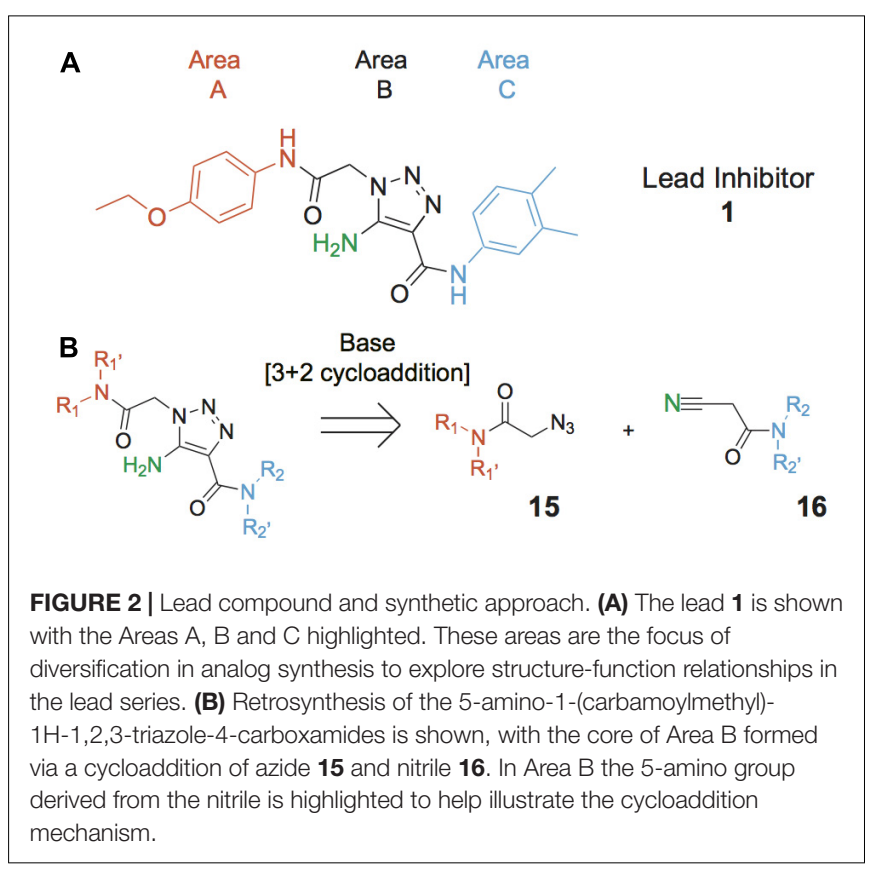

and lyophilized to remove water and DMSO. The resulting crude material was purified via reverse phase HPLC using acetonitrile in deionized $\mathrm{H}_{2} \mathrm{O}$ (with $0.1 \%$ TFA in both solvents) to yield, after evaporation and lyophilization, the desired product.

For compound 7 a variation of synthesis A (synthesis C) was employed in which sodium methoxide was used instead of sodium ethoxide. For this synthesis a mixture of the cyano component $(0.24 \mathrm{mmol})$, and sodium methoxide $(0.26 \mathrm{mmol})$ in methanol $(1.07 \mathrm{~mL})$ was stirred for $30 \mathrm{~min}$ before addition of the azido component $(0.21 \mathrm{mmol})$. The reaction was stirred for $16 \mathrm{~h}$ before treatment with methanol $(0.25 \mathrm{~mL})$ and stirring for $3 \mathrm{~h}$. Methanol $(1 \mathrm{~mL})$ was added, and the reaction was heated at $95^{\circ} \mathrm{C}$ for $2 \mathrm{~h}$. The mixture was treated with deionized water $(25 \mathrm{~mL})$, concentrated $\mathrm{HCl}$ (1 drop), and ethyl acetate $(10 \mathrm{~mL})$. The aqueous layer was treated with saturated aqueous $\mathrm{NaHCO}_{3}$ $(5 \mathrm{~mL})$ and extracted with ethyl acetate $(10 \mathrm{~mL})$. The combined organic extracts were washed with saturated aqueous $\mathrm{NaHCO}_{3}$ $(10 \mathrm{~mL})$, brine $(10 \mathrm{~mL})$, and dried over anhydrous $\mathrm{MgSO}_{4}$ before concentration. The crude material was purified via reverse phase HPLC using acetonitrile in deionized $\mathrm{H}_{2} \mathrm{O}$ (with $0.1 \%$ TFA in both solvents) to yield, after evaporation and lyophilization, the desired product.

Some compounds in the Supplementary Information were synthesized by alternative methods in which an acetylene component replaced the cyano component. The alternate syntheses are described in the Supplementary Methods. Analogs which were not synthesized were obtained from commercial vendors ChemDiv (San Diego, CA, United States) and Vitas-M Laboratory (Champagne, IL).

All compounds were readily soluble in DMSO and were stored as $10 \mathrm{mM}$ frozen $\left(-30^{\circ} \mathrm{C}\right)$ stocks when not in use. 
Selwood et al.

Disarming the Bacterial SOS Response

TABLE 1 | Synthesis and inhibition by lead analogs.<smiles>[R2][Y20]C(=O)Cn1nnc(C(=O)N[R20])c1N</smiles>

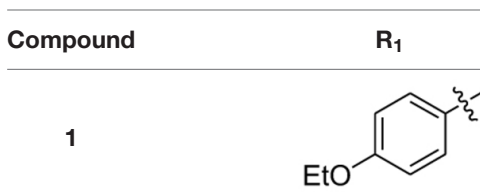

2
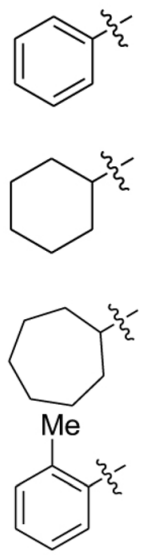

6
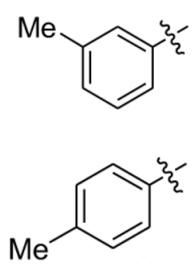

8<smiles>Cc1ccc(C)c(C)c1</smiles>

9

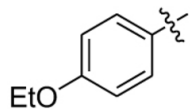

10<smiles>CCOc1ccc(C(C)(C)C)cc1</smiles>

11

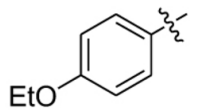

12
E. coli $\mathrm{IC}_{50} / \mu \mathrm{M}^{1}$

$\mathbf{R}_{\mathbf{2}}$

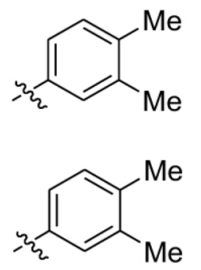

$32 \pm 6$

A/B

nsa

commercial

$>100$

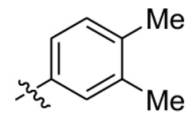

A

27

$44 \pm 4$

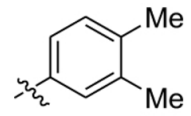

B

34

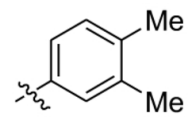

$17 \pm 2$

nsa

commercial

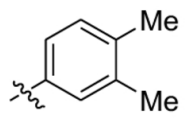

nsa

commercial

$18 \pm 1$

C

21

$15 \pm 2$

B

31

$>100$

na

commercial

$33 \pm 4$

A

32

$15 \pm 2$

n/a

commercial

$19 \pm 3$

B

12

(Continued)

Frontiers in Microbiology | www.frontiersin.org

4

December 2018 | Volume 9 | Article 2961 
TABLE 1 | Continued

\begin{tabular}{|c|c|c|c|c|c|}
\hline Compound & $\mathbf{R}_{1}$ & $\mathbf{R}_{2}$ & E. coli $\mathrm{IC}_{50} / \mu \mathrm{M}^{1}$ & Synthesis $^{2}$ & Yield\% \\
\hline 13 & & & $40 \pm 3$ & B & 33 \\
\hline 14 & & & $9 \pm 1$ & B & 39 \\
\hline
\end{tabular}

${ }^{1}$ IC50 values are the avearge of 4 determinations and the errors are \pm 1 SD. ${ }^{2} \mathrm{~A}-\mathrm{NaOEt}$ conditions. B-CS2CO3 conditions, C-NaOMe conditions.

\section{FIAsH-LexA Cleavage Assay}

$\mathrm{IC}_{50}$ values were routinely determined using the E. coli FlAsHLexA cleavage assay previously used to perform HTS (Mo et al., 2018). In this assay RecA-promoted LexA cleavage is monitored using fluorescence polarization. The E. coli FlAsH-LexA and RecA were constructed, expressed and purified as previously described (Mo et al., 2018). The conditions were $100 \mathrm{nM} \mathrm{E.} \mathrm{coli}$ FlAsH-LexA, $200 \mathrm{nM}$ RecA, $5 \mu \mathrm{M}$ ssDNA (SKBT25: GCG TGT GTG GTG GTG TGC) (Tracy and Kowalczykowski, 1996), $5 \mu \mathrm{M}$ ATP $\gamma \mathrm{S}$ in $100 \mathrm{mM}$ Tris- $\mathrm{HCl}, \mathrm{pH} 6.5,150 \mathrm{mM} \mathrm{NaCl}, 5 \mathrm{mM}$ $\mathrm{MgCl}_{2}, 0.1 \mathrm{mM}$ TCEP, and $0.01 \%$ (w/v) Pluronic-F127. Reactions were performed in 384-well plates and components were added as $10 \mu \mathrm{L}$ additions of ATP $\gamma$ S, ssDNA and RecA, in buffer and $10 \mu \mathrm{L}$ of E. coli FlAsH-LexA in buffer using a Janus liquid handler (Perkin-Elmer). Compound was added as a DMSO solution using a pin tool, and the final concentration of DMSO in the reaction was $1.2 \%$. Once the reaction components were combined, reactions were centrifuged for $1 \mathrm{~min}$ at $500 \mathrm{rpm}$ and incubated for $30 \mathrm{~min}$ at room temperature. Reactions were quenched with a $10 \mu \mathrm{L}$ addition of $50 \mathrm{mM}$ EDTA and plates were read on a Tecan Infinite F200 Pro plate reader (Tecan US, Inc., Morrisville, NC, United States). The final assay conditions resulted in 100 $120 \mathrm{mP}$ difference between the uncleaved and cleaved control wells, representing an approximately $60 \%$ cleavage of the E. coli FlAsH-LexA. On each plate 32 positive (-RecA) and 32 negative controls $(+\operatorname{Rec} A)$ in which DMSO without compound was added were used to define the range of $\mathrm{mP}$ and calculate the fraction inhibited.

$\mathrm{IC}_{50}$ values were estimated by non-linear least squares fitting to the data using Equation 1.

$$
\mathrm{FI}=\frac{[\mathrm{I}]^{\mathrm{n}}}{\mathrm{IC}_{50}^{\mathrm{n}}+\mathrm{I}^{\mathrm{n}}}
$$

where FI = Fraction inhibited, $[\mathrm{I}]$ = Concentration of compound and $n=$ Hill coefficient. Fitting was performed using Igor Pro (WaveMetrics Inc., Lake Oswego, OR, United States).

In the FlAsH-LexA cleavage assay the highest compound concentration was $111 \mu \mathrm{M}$ and all of the compounds that demonstrated activity $(1,3,4,5,7,8,10-14,22$, and 23) elicited normal titration curves suggesting that aqueous solubility was maintained up to $111 \mu \mathrm{M}$. Representative titrations for the compounds can be found in the Supplementary Figure 1.

\section{Orthogonal ${ }^{32} \mathrm{P}$-LexA Cleavage Assay}

Full-length $E$. coli and $P$. aeruginosa LexA were engineered with a RRXS phosphorylation site on the N-terminus of the full-length protein, allowing for ${ }^{32} \mathrm{P}$ labeling by protein kinase A to produce ${ }^{32} \mathrm{P}$-LexA, as described previously (Mo et al., 2018). Reactions contained $100 \mathrm{nM}{ }^{32} \mathrm{P}$-LexA, $200 \mathrm{nM}$ RecA and $10 \mu \mathrm{M}$ ATP $\gamma S$ and the buffer conditions were identical to those in the HTS assay. Compounds were added in DMSO and the final concentration was $2 \%$. Reactions were incubated for $30 \mathrm{~min}$ at room temperature after which $2 \times$ Laemmli buffer was added to stop the assay. The stopped reactions were subjected to $15 \%$ SDS-PAGE and the gels were visualized via phosphorimaging on a Typhoon imager (GE Healthcare BioSciences, Marlborough, MA, United States). The intact and cleaved bands were quantified using Quantity One (Bio-Rad, Hercules, CA, United States) and the fraction inhibited was calculated. As for the HTS assay, controls contained DMSO and the negative controls contained RecA while the positive controls did not. Plots of fraction inhibited against compound concentration were fitted to Equation 1.

\section{Electrophoretic Mobility Shift Assay}

For the electrophoretic mobility shift assay (EMSA) full-length, catalytically inactive LexA-S119A was used (Mo et al., 2014). Increasing concentrations $(0-1 \mu \mathrm{M})$ of LexA-S119A were mixed with $10 \mathrm{nM}$ SOS operator DNA labeled with Cy5 in EMSA running buffer (70 mM Tris- $\mathrm{HCl} \mathrm{pH} \mathrm{7.5,10} \mathrm{mM} \mathrm{MgCl}_{2}, 150 \mathrm{mM}$ $\mathrm{NaCl}, 5 \mathrm{mM}$ DTT, $0.1 \mathrm{mg} / \mathrm{ml} \mathrm{BSA}, 10 \mathrm{ng} / \mu \mathrm{L}$ ssDNA, $5 \%$ glycerol, $0.04 \%$ bromophenol blue) in the presence of $50 \mu \mathrm{M}$ of compound (or DMSO carrier). After incubation at room temperature for $30 \mathrm{~min}, 20 \mu \mathrm{L}$ of each reaction was subjected to $6 \%$ native PAGE. Gels were visualized on a Typhoon Imager using default fluorescence filter settings for Cy5. Gel bands were quantified using Image (NIH, Bethesda, MD, United States) to determine the fraction of bound DNA at each LexA concentration. Data were fitted to a variable-slope sigmoidal dose-response curve.

\section{Cell-Based SOS Reporter Assay}

An E. coli MG1655 strain lacking sulA $(\Delta$ sulA) and the tolC transporter $(\Delta t o l C)$ (Mo et al., 2016) was transformed with a reporter plasmid in which $g f p$ expression was under the control of the recA promoter (pMS201 pRecA GFP) (Zaslaver et al., 2006). To perform assays overnight, cultures of the reporter strain were diluted 100 -fold in $\mathrm{M} 9$ minimal media and grown at $37^{\circ} \mathrm{C}$ 
with agitation to an $\mathrm{OD}_{595}$ of $\sim 0.6$. For each reaction sample $100 \mu \mathrm{L}$ of culture were mixed with $100 \mu \mathrm{L}$ of M9 minimal media containing ciprofloxacin $(256 \mathrm{ng} / \mathrm{mL})$. Pre-diluted compounds were added $(5 \mu \mathrm{L})$ in DMSO and cultures were incubated at $37^{\circ} \mathrm{C}$ with agitation for $2 \mathrm{~h}$ after which the cells were fixed by adding $200 \mu \mathrm{L}$ of phosphate buffered saline, $\mathrm{pH} 7.4$ containing $1 \%$ paraformaldehyde. After $1 \mathrm{~h}$ of fixing, the cells were spun down at 4,000 rpm and re-suspended in phosphate buffered saline, $\mathrm{pH}$ 7.4. Fixed cells were analyzed using flow cytometry (BD FACSCalibur, Ex/Em: $488 \mathrm{~nm} / 530 \mathrm{~nm}$ ) and the mean fluorescence of 20,000 cells in each condition was recorded.

\section{Frequency of Resistance}

A starter culture of $\triangle$ tolC E. coli was cultured overnight at $37^{\circ} \mathrm{C}$ with shaking in LB broth. The next day the culture was diluted $3 \times 10^{7}$-fold in to LB broth. The dilution was used to produce four sets of twelve cultures, each containing $1 \mathrm{~mL}$. To one set was added $10 \mu \mathrm{L}$ of deionized $\mathrm{H}_{2} \mathrm{O}$ plus $10 \mu \mathrm{L}$ of DMSO, to the second set was added $10 \mu \mathrm{L}$ of $125 \mathrm{ng} / \mathrm{mL}$ ciprofloxacin in deionized $\mathrm{H}_{2} \mathrm{O}$ plus $10 \mu \mathrm{L}$ of DMSO, to the third set was added $10 \mu \mathrm{L}$ of deionized $\mathrm{H}_{2} \mathrm{O}$ plus $10 \mu \mathrm{L}$ of a $10 \mathrm{mM}$ solution of 14 in DMSO and to the fourth set was added $10 \mu \mathrm{L}$ of $125 \mathrm{ng} / \mathrm{mL}$ ciprofloxacin in deionized $\mathrm{H}_{2} \mathrm{O}$ plus $10 \mu \mathrm{L}$ of 14 in DMSO. The final concentration of ciprofloxacin $(1.25 \mathrm{ng} / \mathrm{mL})$ was below the MIC for ciprofloxacin which was determined to be $5 \mathrm{ng} / \mathrm{mL}$.

The 48 cultures were incubated at $37^{\circ} \mathrm{C}$ with shaking for $48 \mathrm{~h}$. To determine the population size, spot plating was performed starting with $1 \mu \mathrm{L}$ of the cultures diluted $10^{5}$-fold. A $100 \mu \mathrm{L}$ aliquot of each $10^{5}$-fold dilution was transferred to a 96-well plate and serially diluted (10-fold dilutions) into LB broth. The dilutions $(5 \mu \mathrm{L})$ were spotted on LB agar plates and the plates were incubated overnight at $37^{\circ} \mathrm{C}$. To determine the rifampin resistant population, $999 \mu \mathrm{L}$ of each $1 \mathrm{~mL}$ culture was centrifuged at $6000 \mathrm{rpm}$ for $10 \mathrm{~min}$ to remove the cells from solution and the cells were suspended in $100 \mu \mathrm{L}$ of autoclaved $0.15 \mathrm{M}$ $\mathrm{NaCl}$. The $100 \mu \mathrm{L}$ solutions were plated on the LB plates containing $100 \mu \mathrm{g} / \mathrm{mL}$ rifampin and incubated for 2 days at $37^{\circ} \mathrm{C}$. Following counting of the colonies the program bz-rates (Gillet-Markowska et al., 2015) was used to estimate mutation rates.

\section{RESULTS}

Among the leads isolated from the HTS performed for inhibitors of RecA*-mediated LexA cleavage, lead $\mathbf{1}$ was selected for progression (Figure 2A). In the initial HTS, the parent 5-amino1-(carbamoylmethyl)-1H-1,2,3-triazole-4-carboxamide, 1, had an $\mathrm{IC}_{50}$ value of $32 \mu \mathrm{M}$ (Table 1). This chemotype was well behaved in the HTS, producing close to $100 \%$ inhibition, and appeared to offer the most chemical tractability to allow for the construction of structure activity relationships (SARs). Furthermore, as LexA cleavage involves formation of a $\beta$-turn at the site of self-cleavage (Lee et al., 2005; Whitby et al., 2011), the structural similarity of $\mathbf{1}$ to $\beta$-turn mimetics also suggested that structure-activity relationships could inform on the possible mode of inhibitor action.
In order to better understand SARs, a modular synthesis was devised that would permit generation of informative analogs. While the construction of 5-amino-1,4-disubstituted1,2,3-triazoles has been extensively investigated (Tome, 2004) no synthetic routes to 5-amino-1-(carbamoylmethyl)- $1 H$-1,2,3triazole-4-carboxamides based on $\mathbf{1}$ have yet been reported.

Initial synthetic routes that proceeded via the generation of two potential carboxylic acid intermediates followed by peptide couplings to vary the left- and right-hand portions of the final product were unsuccessful. These reactions were low yielding and/or the precursors were prone to decomposition. A more successful strategy proved to be to proceed via the simple structural intermediates, azides (15) for the left-hand portion and nitriles (16) for the right-hand portion (Figure 2B). These intermediates were either synthesized in 1-2 steps (Hering et al., 2005; Ju et al., 2006; Srinivasan et al., 2006; Ng et al., 2008; Xia et al., 2014) or purchased directly and could be combined via known base-mediated conditions to produce the desired aminotriazoles via a $[3+2]$ cycloaddition.

Three sets of reagents that have been previously reported to facilitate such cyclizations were screened: stoichiometric sodium methoxide (Alfred, 1970; L'abbé and and Beenaerts, 1989; Julino and Stevens, 1998), stoichiometric sodium ethoxide (Hoover and Day, 1956; Livi et al., 1979), and catalytic cesium carbonate (Krishna et al., 2015). In most cases the choice of base between stoichiometric sodium ethoxide and catalytic cesium carbonate had little to no impact on the yield (e.g., 1, Table 1). Overall most reactions were successful using the cesium carbonate conditions, however, yields using this route were affected by the time and temperature of the reaction. Using either the sodium ethoxide or catalytic cesium carbonate routes readily permitted modular access to a large variety of analogs, as demonstrated by the fact that aromatic, heteroaromatic, and non-aromatic groups for $\mathrm{R}_{1}$ and $\mathrm{R}_{2}$ were tolerated (Table $\mathbf{1}$ ). This modular approach thus allowed for systematic variation and investigation of structure activity relationships.

\section{Structure Activity Relationships}

Initial medicinal chemistry efforts focused on developing an understanding of the necessary features to improve potency. The three areas (A, B, and C) in Figure 2A were systematically investigated and the $\mathrm{IC}_{50}$ values for selected compounds are listed in Table 1 with additional data shown in Supplementary Table 1. Approaches used to probe the binding of compounds of this class included amino group replacement, linker methylation and $\mathrm{N}$-methylation, methyl probing of the aryl rings, homologated variations, and non-aromatic variations. $\mathrm{IC}_{50}$ values were determined using the FlAsH-LexA cleavage assay.

In the linker connecting areas $\mathrm{A}$ and $\mathrm{B}$, both mono- and bis-methylated compounds (17 and 18) showed no measurable activity, suggesting that substitution was not tolerated at the methylene linker. Similarly, methylation of the amide of the linker, 19, also abrogated activity. The inability to tolerate substitution in the linker region suggested that it likely lies in a narrow groove and that attempts to modify this area could impact the conformations accessed by the lead. With the linker area appearing not amenable to modification, the 
aromatic portion of area A was investigated. Replacement of the para-ethoxy group substituted phenyl ring with an unsubstituted phenyl, 2, benzyl, 20, or phenethyl group, 21, led to loss of activity. However, replacement of the phenyl ring with a cyclohexyl ring, 3, or a cycloheptyl ring, 4, returned activity, suggesting that aromaticity was a larger restriction than hydrophobicity. Systematic variation of methyl functionalization on the phenyl ring revealed that substitution at the meta position, 6, was not tolerated whereas substitution on the ortho, 5 , and para, 7, positions were preferred. Beyond the single methyl functionalization, mono-substitution at the ortho position on the phenyl showed steric preferences with activities: $\mathrm{Me}(5)>\mathrm{Et}$ (22) $>$ OMe (23) > OEt (24) $=\mathrm{H}$ (2). Bis-substitution on the aryl ring was additionally investigated with for example, 8, showing that combination of ortho- and para-substitution was tolerated but not significantly superior to ortho-substitution alone, 5. In summary, probing of area A revealed interesting substrate preferences but failed to produce a significant increase in potency.

Additional investigations in area $\mathrm{B}$ also did not reveal a means to increase potency. Replacement of the amine by hydrogen (25), methyl (26), or ethyl (27) all rendered compounds inactive, suggesting that the amine was making contacts essential for activity. Supporting this conclusion was the finding that monosubstitution on the amine by acetyl (28) was tolerated but with reduced potency.

Probing of area $\mathrm{C}$ proved more fruitful. As with area $\mathrm{A}$, the amide linker appeared important as methylation was not tolerated (29). Probing of the phenyl moiety indicated that its presence and correct positioning are critical. The importance of this ring was indicated by the intolerance to replacement by cyclohexyl (30) or methyl (31) groups, and the need for correct positioning was indicated by the intolerance to the replacement of the phenyl ring by benzyl (32) or phenethyl (33). The importance of substitution on the phenyl ring was investigated by systematic methyl substitution around the phenyl ring. Consistent with the meta- and para- substitution pattern on area $\mathrm{C}$ of $\mathbf{1}$, this analysis indicated that ortho substitution, 9, was not tolerated whereas individual meta, 10, and para, 11, substitutions were allowed. Heteroatom inclusion was also tolerated in Area C, as shown by ester-containing variation 12, and pyridyl derivative 13. However, compound 14, 5-amino-1-\{2-[(4-ethoxyphenyl)amino]-2-oxoethyl $\}$-N-phenyl$1 \mathrm{H}-1,2,3$-triazole-4-carboxamide, with no substitution on the phenyl ring proved to be the most potent compound tested in this series with an $\mathrm{IC}_{50}$ of $9 \mu \mathrm{M}$.

Before proceeding to additional analysis, cytotoxicity testing with HG2 cells was performed for select compounds, including 1 and 14. Both the initial lead 1 and the most potent analog 14 showed no appreciable toxicity $\left(\mathrm{CC}_{50}\right.$ of $277 \mu \mathrm{M}$ and $>500 \mu \mathrm{M}$, respectively). Due to the increased potency and lack of cytotoxicity, the mechanism and activity of compound $\mathbf{1 4}$ was examined in more detail as described below.

\section{Characteristics of Compound 14}

A suite of assays was utilized to examine $\mathbf{1 4}$ in order to confirm specific inhibition against LexA and demonstrate SOS suppression in cells. To confirm the findings from the

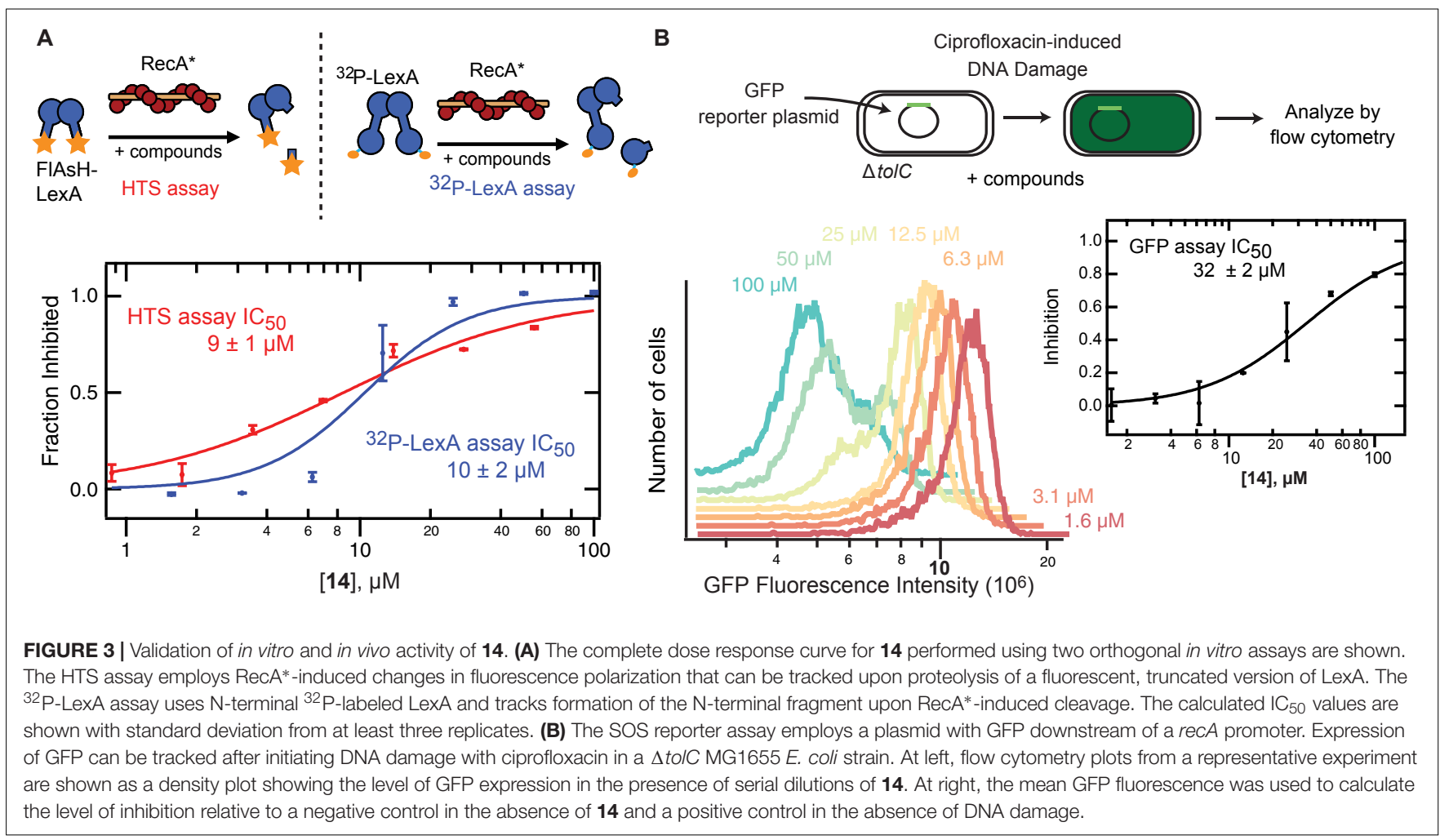


FlAsH-LexA cleavage assay, a fluorescence-independent assay using a full-length version of $E$. coli LexA was employed. The full-length LexA contained a PKA phosphorylation site at the $\mathrm{N}$-terminus that allowed ${ }^{32} \mathrm{P}$ labeling, such that the extent of auto-proteolysis can be visualized by phosphor-imaging following SDS-PAGE. A plot of the titration curve of $\mathbf{1 4}$ obtained using this methodology is shown along with a titration obtained using the FlAsH-LexA assay in Figure 3A. The $\mathrm{IC}_{50}$ of $10 \pm 1 \mu \mathrm{M}$ indicates that the $\mathrm{IC}_{50}$ obtained using the fluorescently labeled truncated E. coli LexA in the HTS assay $(9 \pm 1 \mu \mathrm{M})$ was not due to a fluorescence artifact, and that similar potency is observed with full-length and truncated LexA. Interestingly, a similar $\mathrm{IC}_{50}$ value was obtained when the slow cleavage in the absence of RecA* was monitored (Supplementary Figure 2A). This suggests that 14 binds specifically to LexA, which is further supported by the observation of a thermal shift assay of LexA in the presence of $\mathbf{1 4}$ (Supplementary Figure 2B).

The dual activities of LexA, DNA binding and protease activity, permit confirmation of specificity. If 14 inhibits RecA*mediated LexA cleavage in the expected manner, it would be predicted to inhibit the protease function of LexA, but not to alter DNA binding. To examine LexA binding to DNA in the presence of 14 an EMSA was employed. As with 1 (Mo et al., 2018), LexA showed similar DNA binding affinity in the presence or absence of 14 (Supplementary Figure 3). This observation confirms that the effects in the HTS and ${ }^{32} \mathrm{P}$-LexA assays are not due to non-specific aggregation of LexA or other artifacts. Another important consideration is the permeability of $\mathbf{1 4}$ in to the bacteria. Permeability was assessed using a $\Delta$ tolC strain of E. coli containing a plasmid that contained the GFP gene under the control of the recA promotor (Mo et al., 2018). Compound 14 inhibited the appearance of GFP fluorescence in a dosedependent manner with an $\mathrm{IC}_{50}$ value of $32 \pm 2 \mu \mathrm{M}$ indicating permeability into the $\Delta$ tolC strain of $E$. coli (Figure 3B), without impacting cell size (Supplementary Figure 4). The less potent value compared to in vitro values suggests that even in the efflux-compromised E. coli strain there still remain barriers to entry.

Although the permeability remains in need of further improvement, we also examined whether 14 could suppress the downstream effects of the SOS response in vivo. With the knowledge that the $\mathrm{IC}_{50}$ for permeability in the $\triangle$ tolC strain of E. coli was $32 \pm 2 \mu \mathrm{M}$, a concentration of $100 \mu \mathrm{M} 14$ was used to assess the ability of $\mathbf{1 4}$ to suppress the ciprofloxacin-induced appearance of resistance to rifampicin. As can be seen from Figure 4, the lead $\mathbf{1 4}$ was effective in reducing the appearance of resistance to rifampicin. In the presence of $\mathbf{1 4}$ alone, the mutation rates were comparable to DMSO alone controls. Conversely, exposure to a sub-MIC concentration $(1.25 \mathrm{ng} / \mathrm{mL})$ of ciprofloxacin produced an induction of mutagenesis. In the presence of ciprofloxacin and $\mathbf{1 4}$ together, an approximately threefold decrease in the per generation mutation rate was observed relative to ciprofloxacin alone.

\section{Cross-Species Reactivity}

The HTS and medicinal chemistry efforts were directed at the inhibition of E. coli LexA auto-proteolysis. To determine

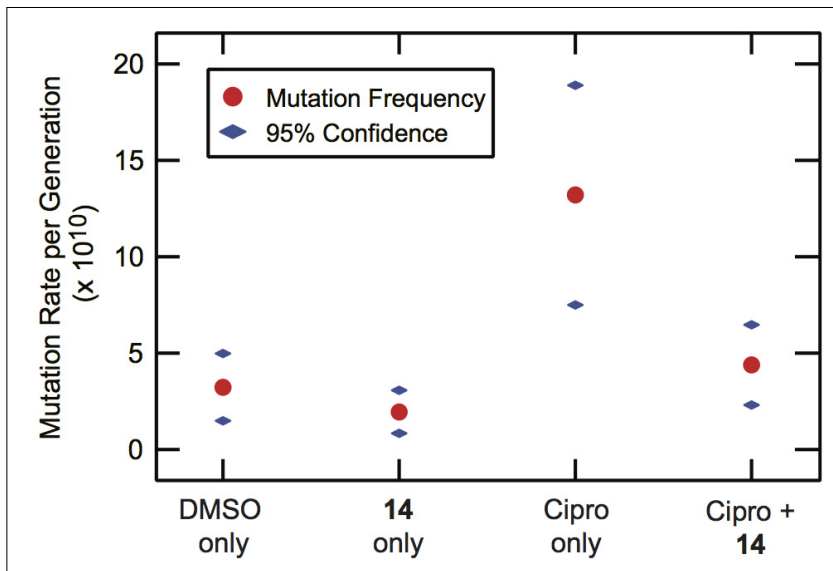

FIGURE 4 | Suppression of ciprofloxacin-induced mutagenesis by 14. $\Delta$ to/C MG1655 E. coli cultures were grown in the presence or absence of $\mathbf{1 4}$ $(100 \mu \mathrm{M})$ and/or a sub-MIC level of ciprofloxacin $(1.25 \mathrm{ng} / \mathrm{mL})$. The cultures were plated without selection to determine total population size and on selective rifampin-containing media $(100 \mu \mathrm{g} / \mathrm{mL})$ to quantify the frequency of rifampin-resistance in the population. The mutational frequency was converted to a per-generation mutation rate, with the rate and 95\% confidence interval shown. The rate data were calculated based on at least twelve independent cultures under each condition.

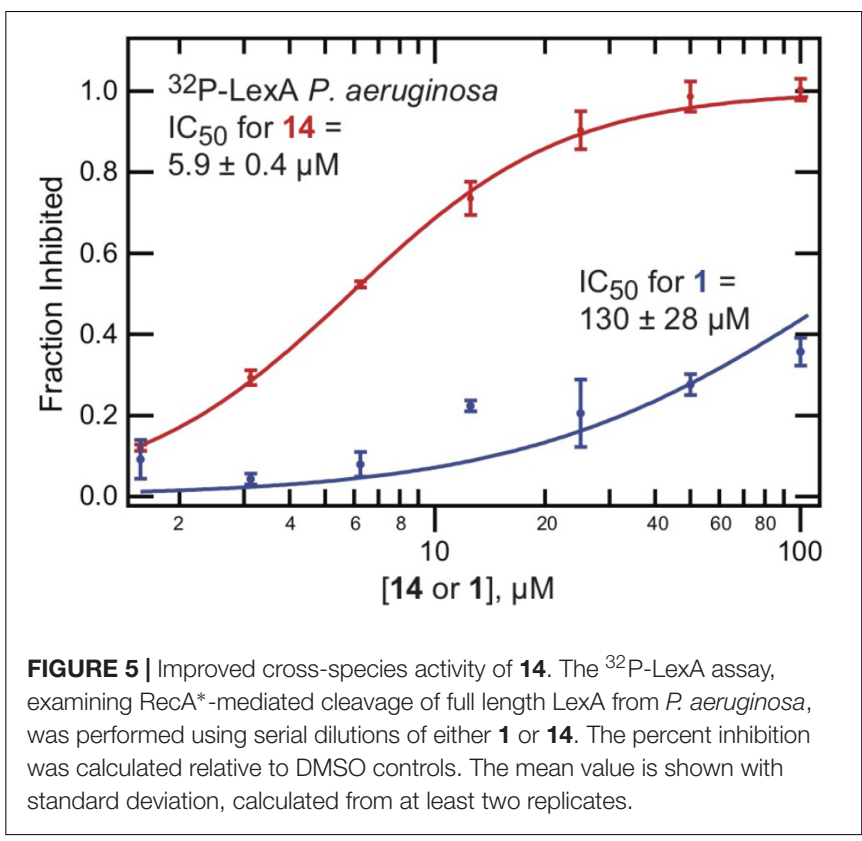

the extent of cross-species reactivity, the effectiveness of $\mathbf{1 4}$ in inhibiting the RecA-promoted auto-proteolysis of Pseudomonas aeruginosa LexA was examined. As can be seen from Table 1 and Figure 5, compound $\mathbf{1 4}$ inhibited the RecA-mediated auto-proteolysis of $P$. aeruginosa LexA with similar potency $\left(\mathrm{IC}_{50}=5.9 \pm 0.4 \mu \mathrm{M}\right)$ to that demonstrated with full-length E. coli LexA $\left(\mathrm{IC}_{50}=10 \pm 1 \mu \mathrm{M}\right)$. This behavior was not observed with 1 (Figure 5) which was a less potent inhibitor of RecA*-induced auto-proteolysis of full-length $P$. aeruginosa LexA $\left(\mathrm{IC}_{50}=130 \pm 28 \mu \mathrm{M}\right)$. Thus, minor modifications 
to 14 compared to $\mathbf{1}$ had a significant effect on crossspecies reactivity and permits potentially expanded species breadth.

\section{DISCUSSION}

While the HTS for inhibitors of RecA*-mediated LexA cleavage produced several chemotypes, the 5-amino-1(carbamoylmethyl)-1H-1,2,3-triazole-4-carboxamide scaffold appeared the most amenable for advancement. The low cytotoxicity and the $\beta$-turn mimetic-like structure (see below) were important considerations in the choice to advance this chemotype. A particularly important consideration was the chemical tractability of the lead compound, which permitted the development of a highly modular synthesis that allowed for an initial survey of structure-activity relationships. Our synthetic approach is important because compounds containing the privileged 5-amino-1-(carbamoylmethyl)-1H1,2,3-triazole-4-carboxamide scaffold have been used to target broad categories of biological activity. Targets have included C3d of the immune response (Morikis and Gorham, 2016), Mycobacterium tuberculosis proteasome (Mehra et al., 2015, 2016), microRNA for the treatment of certain cancers (Calin et al., 2002), and a wide range of other diseases (Tili et al., 2007; Huang et al., 2010, 2012, 2013).

Inhibition of the SOS response can now be added to the list of uses for the 5-amino-1-(carbamoylmethyl)-1H-1,2,3-triazole4-carboxamide scaffold. More specifically, the similar $\mathrm{IC}_{50}$ values for $\mathbf{1 4}$ in the fluorescence-based LexA cleavage assay and an orthogonal ${ }^{32} \mathrm{P}$-LexA \pm RecA assay suggests on-target activity. This effect appears specific for the self-cleavage activity of LexA, because EMSA testing indicated that $\mathbf{1 4}$ does not interfere with the DNA binding ability of LexA. The fact that one LexA function is inhibited while the other is preserved further suggests that 14 is not a Pan-Assay Interference (PAINS) inhibitor (Aldrich et al., 2017). While the data suggest $\mathbf{1 4}$ binds specifically, the exact binding site is not clear. We have previously speculated that a $\beta$-turn mimetic may prove a useful strategy for targeting the LexA active site given that a $\beta$-turn formation plays a role in self-cleavage (Mo et al., 2016). Indeed, speculation that this scaffold could function as a $\beta$-turn mimetic was one reason for advancing the 5-amino-1-(carbamoylmethyl)1H-1,2,3-triazole-4-carboxamide. The fact that substitutions that likely perturb the conformational dynamics, such as $\mathrm{N}$-methylation of the amide bonds, is consistent with this hypothesis. Nonetheless, the exact target of lead 1 or analog 14 awaits elucidation through structural or mutational studies and allosteric inhibition may well be the mechanism of action due to the inaccessibility of the active site to all but its natural substrate (Culyba et al., 2015).

One likely driving force for the frequent use of this scaffold in varied therapeutic applications is its low cytotoxicity, as evidenced by the $\mathrm{CC}_{50}$ values of $277 \mu \mathrm{M}$ and $>500 \mu \mathrm{M}$. Other properties of $\mathbf{1 4}$ also indicate that it is a promising starting point, although ongoing optimization is needed. The properties of the molecule fall within Lipinski's rules for drug-likeness
(Lipinski et al., 1997): it has a molecular weight of $380.4(<500)$, three hydrogen bond donors $(\leq 5)$, six hydrogen bond acceptors $(\leq 10)$ and a $c \log \mathrm{P}$ of $1.63(\leq 5)$. In comparison to oral drugs for non-infectious diseases, antibacterial compounds tend to have greater polarity (O'Shea and Moser, 2008; Brown et al., 2014) which provides better solubility (useful for IV drugs) and may enable improved permeability through the outer membrane of Gram-negative bacteria (Nikaido, 2003; Brown et al., 2014). Low lipophilicity is also preferred to avoid off-target activities and cytotoxicity (Livi et al., 1979). Compound $\mathbf{1 4}$ has a polar surface area of $124 \AA^{2}$ which is below the value of $140 \AA^{2}$ above which permeability is typically an issue. These properties define $\mathbf{1 4}$ as a drug-like small molecule modulator of the SOS response.

For small molecule SOS modulators to prove useful to address therapeutic challenges, there are two important features of the molecules which will be necessary. First, the molecules must have sufficient breadth to allow for their use against multiple potential pathogens. Although our initial lead 1 showed only limited reactivity against LexA from $P$. aeruginosa (Figure 5), our optimization around the scaffold encouragingly revealed 14 as an analog with similar potency against LexA from E. coli and $P$. aeruginosa. This development is important because pathogens such as $P$. aeruginosa are associated with chronic infections. Frequent antibiotic exposure in patients with cystic fibrosis or other immunocompromising conditions make the risks of acquired resistance particularly high in these patients. In addition to cross-species reactivity, small molecule modulators must also show sufficient potency in vivo. The improved analog 14 shows SOS inhibition activity using the GFP reporter assay in the efflux compromised $\triangle$ tolC E. coli strain. Encouragingly, at high concentrations, $\mathbf{1 4}$ also reduced the rate of ciprofloxacininduced mutation (Figure 4). Although these activities against E. coli are promising, these results suggest that the potency of the current leads requires additional improvement, especially because genetic studies not only suggest that potent SOS inhibition is necessary to fully potentiate antibiotic effects but also reveal that mutation rates can be reduced even further (Mo et al., 2016).

The trigger for the activation of the SOS response is genotoxic stress which many antibiotics induce. Molecules that attenuate the activation of the SOS response could therefore reduce the ability of pathogens to adapt and evolve under antimicrobial treatment. Evidence suggests that such a therapeutic would be most effective when used as an adjuvant to an antibiotic whose mechanism of action involves directly damaging DNA, e.g., fluoroquinolones (Mo et al., 2016). The improvements in potency and crossspecies activity with 14 suggest that although ongoing work is needed to improve existing leads, discovery of such a therapeutic DISARMER is a feasible pursuit. Combining fluoroquinolones with a potent DISARMER could provide advantages similar to those that $\beta$-lactamase inhibitors have provided for $\beta$-lactam antibiotic therapy. These possible advantages include extension of the useful lifetime of an antibiotic, increased susceptibility of bacteria to antibiotics, and slowed acquisition of resistance, all of which 
offer alternative strategies to address the challenges posed by bacterial pathogens.

\section{AUTHOR CONTRIBUTIONS}

TS, RK, AR, and SB designed the experiments. TS, BL, CM, MC, and $\mathrm{ZH}$ performed the experiments. TS, RK, and $\mathrm{SB}$ analyzed the data. TS, RK, and SB wrote the manuscript. All authors reviewed and edited the manuscript.

\section{FUNDING}

This work was supported by the National Institutes of Health (DP2-GM105444 and R01-GM127593 to RK), and

\section{REFERENCES}

Alam, M. K., Alhhazmi, A., Decoteau, J. F., Luo, Y., and Geyer, C. R. (2016). RecA inhibitors potentiate antibiotic activity and block evolution of antibiotic resistance. Cell Chem. Biol. 23, 381-391. doi: 10.1016/j.chembiol.2016.02.010

Aldrich, C., Bertozzi, C., Georg, G. I., Kiessling, L., Lindsley, C., Liotta, D., et al. (2017). The ecstasy and agony of assay interference compounds. ACS Infect. Dis. 3, 259-262. doi: 10.1021/acscentsci.7b00069

Alfred, H. G. L. (1970). Reactions of vinyl azides, and $\beta$-haloalkyl azides with active methylene compounds. Synthesis of 1-vinyl-1,2,3-triazoles. J. Heterocycl. Chem. 7, 361-366. doi: 10.1002/jhet.5570070218

Beaber, J. W., Hochhut, B., and Waldor, M. K. (2004). SOS response promotes horizontal dissemination of antibiotic resistance genes. Nature 427, 72-74. doi: 10.1038/nature02241

Bellio, P., Di Pietro, L., Mancini, A., Piovano, M., Nicoletti, M., Brisdelli, F., et al. (2017). SOS response in bacteria: inhibitory activity of lichen secondary metabolites against Escherichia coli RecA protein. Phytomedicine 29, 11-18. doi: 10.1016/j.phymed.2017.04.001

Boucher, H. W., Talbot, G. H., Bradley, J. S., Edwards, J. E., Gilbert, D., Rice, L. B., et al. (2009). Bad bugs, no drugs: no ESKAPE! An update from the infectious diseases society of America. Clin. Infect. Dis. 48, 1-12. doi: 10.1086/595011

Brown, D. G., May-Dracka, T. L., Gagnon, M. M., and Tommasi, R. (2014). Trends and exceptions of physical properties on antibacterial activity for gram-positive and gram-negative pathogens. J. Med. Chem. 57, 10144-10161. doi: 10.1021/ jm501552x

Brown, E. D., and Wright, G. D. (2016). Antibacterial drug discovery in the resistance era. Nature 529, 336-343. doi: 10.1038/nature17042

Calin, G. A., Dumitru, C. D., Shimizu, M., Bichi, R., Zupo, S., Noch, E., et al. (2002). Nonlinear partial differential equations and applications: frequent deletions and down-regulation of micro- RNA genes miR15 and miR16 at 13q14 in chronic lymphocytic leukemia. Proc. Natl. Acad. Sci. U.S.A. 99, 15524-15529. doi: 10.1073/pnas.242606799

Cirz, R. T., Chin, J. K., Andes, D. R., de Crécy-Lagard, V., Craig, W. A., and Romesberg, F. E. (2005). Inhibition of mutation and combating the evolution of antibiotic resistance. PLoS Biol. 3:e176. doi: 10.1371/journal.pbio. 0030176

Cirz, R. T., and Romesberg, F. E. (2007). Controlling mutation: intervening in evolution as a therapeutic strategy. Crit. Rev. Biochem. Mol. Biol. 42, 341-354. doi: $10.1080 / 10409230701597741$

Clatworthy, A. E., Pierson, E., and Hung, D. T. (2007). Targeting virulence: a new paradigm for antimicrobial therapy. Nat. Chem. Biol. 3, 541-548. doi: $10.1038 /$ nchembio.2007.24

Culyba, M. J., Kubiak, J. M., Mo, C. Y., Goulian, M., and Kohli, M. (2018). Non-equilibrium repressor binding kinetics link DNA damage dose to transcriptional timing within the SOS gene network. PLoS Genet. 14:e1007405. doi: 10.1371/journal.pgen.1007405 the Harrington Discovery Institute Scholar-Innovator Award (to RK).

\section{ACKNOWLEDGMENTS}

The authors thank Angela Corona, Christine Debouck, Charles McOsker, Richard W. Scott, George L. Trainor, and Jay E. Wrobel for insightful discussions.

\section{SUPPLEMENTARY MATERIAL}

The Supplementary Material for this article can be found online at: https://www.frontiersin.org/articles/10.3389/fmicb. 2018.02961/full\#supplementary-material

Culyba, M. J., Mo, C. Y., and Kohli, R. M. (2015). Targets for combating the evolution of acquired antibiotic resistance. Biochemistry 54, 3573-3582. doi: 10.1021/acs.biochem.5b00109

Da Re, S., Garnier, F., Guérin, E., Campoy, S., Denis, F., and Ploy, M. C. (2009). The SOS response promotes qnrB quinolone-resistance determinant expression. EMBO Rep. 10, 929-933. doi: 10.1038/embor.2009.99

Dörr, T., Lewis, K., and Vulić, M. (2009). SOS response induces persistence to fluoroquinolones in Escherichia coli. PLoS Genet. 5:e1000760. doi: 10.1371/ journal.pgen. 1000760

Dörr, T., Vulić, M., and Lewis, K. (2010). Ciprofloxacin causes persister formation by inducing the TisB toxin in Escherichia coli. PLoS Biol. 8:e1000317. doi: 10.1371/journal.pbio.1000317

Dwyer, D. J., Camacho, D. M., Kohanski, M. A., Callura, J. M., and Collins, J. J. (2012). Antibiotic-induced bacterial cell death exhibits physiological and biochemical hallmarks of apoptosis. Mol. Cell 46, 561-572. doi: 10.1016/j. molcel.2012.04.027

Fischbach, M. A., and Walsh, C. T. (2009). Antibiotics for emerging pathogens. Science (80) 325, 1089-1093. doi: 10.1126/science.1176667

Galhardo, R. S., Hastings, P. J., and Rosenberg, S. M. (2007). Mutation as a stress response and the regulation of evolvability. Crit. Rev. Biochem. Mol. Biol. 42, 399-435. doi: 10.1080/10409230701648502

Gillet-Markowska, A., Louvel, G., and Fischer, G. (2015). bz-rates: a web tool to estimate mutation rates from fluctuation analysis. G3 (Bethesda) 5, 2323-2327. doi: $10.1534 / \mathrm{g} 3.115 .019836$

Gotoh, H., Kasaraneni, N., Devineni, N., Dallo, S. F., and Weitao, T. (2010). SOS involvement in stress-inducible biofilm formation. Biofouling 26, 603-611. doi: 10.1080/08927014.2010.501895

Hering, K. W., Karaveg, K., Moremen, K. W., and Pearson, W. H. (2005). A practical synthesis of kifunensine analogues as inhibitors of endoplasmic reticulum $\alpha$-mannosidase I. J. Org. Chem. 70, 9892-9904. doi: 10.1021/ jo0516382

Hoover, J. R. E., and Day, A. R. (1956). Metabolite analogs. VI. preparation of some analogs of 4-amino-5-imidazole-carboxamide. J. Am. Chem. Soc. 78, 5832-5836. doi: 10.1021/ja01603a033

Huang, Q., Deiters, A., and Gumireddy, K. (2010). MicroRNA Modulators and Method for Identifying and Using the Same. US20100196357A1.

Huang, Q., Deiters, A., and Gumireddy, K. (2012). MicroRNA Modulators and Method for Identifying and Using the Same. US20120010177A1.

Huang, Q., Deiters, A., and Gumireddy, K. (2013). MicroRNA Modulators and Method for Identifying and Using the Same. WO2013019469A1.

Ju, Y., Kumar, D., and Varma, R. S. (2006). Revisiting nucleophilic substitution reactions: microwave-assisted synthesis of azides, thiocyanates, and sulfones in an aqueous medium. J. Org. Chem. 71, 6697-6700. doi: 10.1021/jo061114h

Julino, M., and Stevens, M. F. G. (1998). Antitumour polycyclic acridines. Part 5.1 Synthesis of $7 \mathrm{H}$-pyrido[4,3,2-kl ] acridines with exploitable functionality in the pyridine ring. J. Chem. Soc. Perkin Trans. 1, 1677-84. doi: 10.1039/A800575C 
Kohanski, M. A., Dwyer, D. J., Hayete, B., Lawrence, C. A., and Collins, J. J. (2007). A common mechanism of cellular death induced by bactericidal antibiotics. Cell 130, 797-810. doi: 10.1016/j.cell.2007.06.049

Krishna, P. M., Ramachary, D. B., and Peesapati, S. (2015). Azide-acetonitrile "click" reaction triggered by $\mathrm{Cs} 2 \mathrm{CO} 3$ : the atom-economic, high-yielding synthesis of 5-amino-1,2,3-triazoles. RSC Adv. 5, 62062-62066. doi: 10.1039/ C5RA12308A

L'abbé, G., and Beenaerts, L. (1989). Influence of electron-withdrawing N-1 substituents on the thermal behaviour of 5-azido-1,2,3-triazoles. Tetrahedron 45, 749-756. doi: 10.1016/0040-4020(89)80105-X

Lee, A. M., Ross, C. T., Zeng, B. B., and Singleton, S. F. (2005). A molecular target for suppression of the evolution of antibiotic resistance: inhibition of the Escherichia coli RecA protein by N 6-(1-naphthyl)-ADP. J. Med. Chem. 48, 5408-5411. doi: 10.1021/jm050113z

Ling, L. L., Schneider, T., Peoples, A. J., Spoering, A. L., Engels, I., Conlon, B. P., et al. (2015). A new antibiotic kills pathogens without detectable resistance. Nature 517, 455-459. doi: 10.1038/nature14098

Lipinski, C. A., Lombardo, F., Dominy, B. W., and Feeney, P. J. (1997). Experimental and computational approaches to estimate solubility and permeability in drug discovery and develop ment settings. Adv. Drug Deliv. Rev. 23, 3-25. doi: 10.1016/S0169-409X(00)00129-0

Livi, O., Ferrarini, P. L., Tonetti, I., Smaldone, F., and Zefola, G. (1979). Synthesis and pharmacological activity of 1,2,3-triazole derivatives of naphthalene, quinoline and pyridine. Farm. Ed. Sci. 34, 217-228.

Lu, T. K., and Collins, J. J. (2009). Engineered bacteriophage targeting gene networks as adjuvants for antibiotic therapy. Proc. Natl. Acad. Sci. U.S.A. 106, 4629-4634. doi: 10.1073/pnas.0800442106

Luo, Y., Pfuetzner, R. A., Mosimann, S., Paetzel, M., Frey, E. A., Cherney, M., et al. (2001). Crystal structure of LexA: a conformational switch for regulation of self-cleavage. Cell 106, 585-594. doi: 10.1016/S0092-8674(01)00479-2

McKenzie, G. J., Harris, R. S., Lee, P. L., and Rosenberg, S. M. (2000). The SOS response regulates adaptive mutation. Proc. Natl. Acad. Sci. U.S.A. 97, 6646-6651. doi: 10.1073/pnas.120161797

Mehra, R., Chib, R., Munagala, G., Yempalla, K. R., Khan, I. A., Singh, P. P., et al. (2015). Discovery of new Mycobacterium tuberculosis proteasome inhibitors using a knowledge-based computational screening approach. Mol. Divers. 19, 1003-1019. doi: 10.1007/s11030-015-9624-0

Mehra, R., Chib, R., Munagala, G., Yempalla, K. R., Khan, I. A., Singh, P. P., et al. (2016). Erratum to: discovery of new Mycobacterium tuberculosis proteasome inhibitors using a knowledge-based computational screening approach. Mol. Divers. 20:367. doi: 10.1007/s11030-015-9637-8

Mo, C. Y., Birdwell, L. D., and Kohli, R. M. (2014). Specificity determinants for autoproteolysis of lexa, a key regulator of bacterial SOS mutagenesis. Biochemistry 53, 3158-3168. doi: 10.1021/bi500026e

Mo, C. Y., Culyba, M. J., Selwood, T., Kubiak, J. M., Hostetler, Z. M., Jurewicz, A. J., et al. (2018). Inhibitors of LexA autoproteolysis and the bacterial SOS response discovered by an academic-industry partnership. ACS Infect. Dis. 4, 349-359. doi: 10.1021/acsinfecdis.7b00122

Mo, C. Y., Manning, S. A., Roggiani, M., Culyba, M. J., Samuels, A. N., Sniegowski, P. D., et al. (2016). Systematically altering bacterial SOS activity under stress reveals therapeutic strategies for potentiating antibiotics. MSphere 1:e163-16. doi: 10.1128/mSphere.00163-16

Morikis, D., and Gorham, R. D. J. (2016). Complement C3d-binding Compounds. WO2016179057A1.

Ng, S. L., Yang, P.-Y., Chen, K. Y.-T., Srinivasan, R., and Yao, S. Q. (2008). "Click” synthesis of small-molecule inhibitors targeting caspases. Org. Biomol. Chem. 6, 844-847. doi: 10.1039/B718304F

Nikaido, H. (2003). Molecular basis of bacterial outer membrane permeability revisited. Microbiol. Mol. Biol. Rev. 67, 593-656. doi: 10.1128/MMBR.67.4.593
O'Shea, R., and Moser, H. E. (2008). Physicochemical properties of antibacterial compounds: implications for drug discovery. J. Med. Chem. 51, 2871-2878. doi: 10.1021/jm700967e

Recacha, E., Machuca, J., Alba, P. D., De Ramos-güelfo, M., DocoboPerez, F., Rodriguez-Beltrán, J., et al. (2017). Quinolone resistance reversion by targeting the SOS response. MBio 8:e971. doi: 10.1128/mBio. 00971-17

Schlacher, K., Pham, P., Cox, M. M., and Goodman, M. F. (2006). Roles of DNA polymerase $\mathrm{V}$ and RecA protein in SOS damage-induced mutation. Chem. Rev. 106, 406-419. doi: 10.1021/cr0404951

Smith, P. A., and Romesberg, F. E. (2007). Combating bacteria and drug resistance by inhibiting mechanisms of persistence and adaptation. Nat. Chem. Biol. 3, 549-556. doi: 10.1038/nchembio.2007.27

Srinivasan, R., Uttamchandani, M., and Yao, S. Q. (2006). Rapid assembly and in situ screening of bidentate inhibitors of protein tyrosine phosphatases. Org. Lett. 8, 713-716. doi: 10.1021/ol052895w

Thaker, M. N., Wang, W., Spanogiannopoulos, P., Waglechner, N., King, A. M., Medina, R., et al. (2013). Identifying producers of antibacterial compounds by screening for antibiotic resistance. Nat. Biotechnol. 31, 922-927. doi: 10.1038/ nbt. 2685

Thi, T., Do López, E., Rodríguez-Rojas, A., Rodríguez-Beltrán, J., Couce, A., Guelfo, J. R., et al. (2011). Effect of recA inactivation on mutagenesis of Escherichia coli exposed to sublethal concentrations of antimicrobials. J. Antimicrob. Chemother. 66, 531-538. doi: 10.1093/jac/dkq496

Tili, E., Michaille, J.-J., Gandhi, V., Plunkett, W., Sampath, D., and Calin, G. A. (2007). miRNAs and their potential for use against cancer and other diseases. Futur. Oncol. 3, 521-537. doi: 10.2217/14796694.3.5.521

Tome, A. C. (2004). Product class 13: 1,2,3-Triazoles. Sci. Synth. 13, 415-601. doi: 10.1055/sos-SD-013-00626

Tracy, R. B., and Kowalczykowski, S. C. (1996). In vitro selection of preferred DNA pairing sequences by the Escherichia coli RecA protein. Genes Dev. 10, 1890-1903. doi: 10.1101/gad.10.15.1890

Whitby, L. R., Ando, Y., Setola, V., Vogt, P. K., Roth, B. L., and Boger, D. L. (2011). Design, synthesis, and validation of a $\beta$-turn mimetic library targeting protein - Protein and peptide - Receptor interactions. J. Am. Chem. Soc. 133, 10184-10194. doi: 10.1021/ja201878v

Wigle, T. J., Sexton, J. Z., Gromova, A. V., Hadimani, M. B., Hughes, M. A., Smith, G. R., et al. (2009). Inhibitors of RecA activity discovered by highthroughput screening: cell-permeable small molecules attenuate the SOS response in Escherichia coli. J. Biomol. Screen 14, 1092-1101. doi: 10.1177/ 1087057109342126

Xia, Y., Chen, L., Lv, S., Sun, Z., and Wang, B. (2014). Microwave-assisted or $\mathrm{Cu}-\mathrm{NHC}$-catalyzed cycloaddition of azido-disubstituted alkynes: bifurcation of reaction pathways. J. Org. Chem. 79, 9818-9825. doi: 10.1021/jo5011262

Zaslaver, A., Bren, A., Ronen, M., Itzkovitz, S., Kikoin, I., Shavit, S., et al. (2006). A comprehensive library of fluorescent transcriptional reporters for Escherichia coli. Nat. Methods 3, 623-628. doi: 10.1038/nmeth895

Conflict of Interest Statement: The authors declare that the research was conducted in the absence of any commercial or financial relationships that could be construed as a potential conflict of interest.

Copyright (๑) 2018 Selwood, Larsen, Mo, Culyba, Hostetler, Kohli, Reitz and Baugh. This is an open-access article distributed under the terms of the Creative Commons Attribution License (CC BY). The use, distribution or reproduction in other forums is permitted, provided the original author(s) and the copyright owner(s) are credited and that the original publication in this journal is cited, in accordance with accepted academic practice. No use, distribution or reproduction is permitted which does not comply with these terms. 